REVIEWS OF MODERN PHYSICS, VOLUME 89, JANUARY-MARCH 2017

\title{
Editorial: From the APS Editor in Chief
}

The journals of the American Physical Society welcome and will continue to welcome manuscripts from all countries, with publication based on scientific merit alone.

Published 3 February 2017

Pierre Meystre

Editor in Chief

American Physical Society

DOI: 10.1103/RevModPhys.89.010001 